\title{
2006-185: INNOVATIVE TECHNIQUES TO TEACH TRANSPORTATION ENGINEERING
}

\section{Yusuf Mehta, Rowan University}

Dr. Mehta is an Assistant Professor at the Department of Civil and Environmental Engineering at Rowan University. Dr. Mehta has extensive experience in teaching transportation engineering, pavement materials and pavement systems. Dr. Mehta has published several technical and educational papers in leading professional organizations. 


\title{
Innovative Techniques to Teach Transportation Engineering
}

\begin{abstract}
The transportation engineering is taught in the junior year as a required course for all civil engineering (CE) students. The course provides an introduction to various aspects of transportation engineering. The course, which is traditionally a lecture course, was redesigned to ensure that every student actively participates and understands the physical elements of transportation design. Throughout the course, the faculty conducted a simulating and engaging exercise of requiring students to solve practical problems during class in teams of two immediately after covering the relevant theory. The practical problems were assigned before any example problems were solved in the class. During the class, the faculty was available to answer any questions they may have. At the end, after following through the solution in class, the correct solution was distributed. This allowed them to see how they thought through the problem and also had a correct solution on file for future reference. The students had to assimilate the information provided and translate it to the problem at-hand. This activity initially frustrated the students because they are traditionally used to following example problems. However, this exercise forced them to take the theoretical concepts and directly apply them to transportation engineering analysis and design problems. Such an activity considerably increased the level of interest and provided a greater satisfaction of tackling the problem, rather than just following set example problems. The global learners remained engaged as they could visualize the relevance of the theory being taught in class, and the more sequential learners after the initial struggle followed the problems through the explanation in class and the solution provided at the end of class. For example, the faculty would explain the vertical curves and then immediately following the theory of vertical curves they had to design the curve according to typical constraints in the field. Individual short quizzes were assigned to ensure that they read and followed the material. All exams were take home team-based exams to be submitted within 48 to 72 hours, in which the team-members could discuss their effort as they presented their solutions to complex design and analysis problems. This paper presents the course outline with a week-by-week breakdown of activities and the typical handouts. The student evaluations reflected that enthusiasm and are also presented in the paper.
\end{abstract}

\section{Problem-Based-Learning}

As the label implies, problem-based learning is an educational approach where an ill-structured problem initiates learning. PBL is necessarily interdisciplinary: By addressing real-world problems, students are required to cross the traditional disciplinary boundaries in their quest to solve the problem. One of the primary features of Problem-Based Learning is that it is studentcentered. "Student-centered" refers to learning opportunities that are relevant to the students, the goals of which are at least partly determined by the students themselves (Gallow De, 2006). This does not mean that the teacher abdicates her authority for making judgments regarding what might be important for students to learn; rather, this feature places partial and explicit responsibility on the students' shoulders for their own learning. Creating assignments and activities that require student input presumably also increases the likelihood of students being motivated to learn. 
A common criticism of student-centered learning is that students, as novices, cannot be expected to know what might be important for them to learn, especially in a subject to which they appear to have no prior exposure. The literature on novice-expert learning does not entirely dispute this assertion; rather, it does emphasize that our students come to us, not as the proverbial blank slates, but as individuals whose prior learning can greatly impact their current learning (Scardamalia 1996). Often they have greater content and skill knowledge than we (and they) would expect. In any case, whether their prior learning is correct is not the issue. Whatever the state of their prior learning, it can both aid and hinder their attempts to learn new information. It is therefore imperative that instructors have some sense of what intellectual currency the students bring with them. The context for learning in PBL is highly context-specific. It serves to teach content by presenting the students with a real-world challenge similar to one they might encounter were they a practitioner of the discipline. Teaching content through skills is one of the primary distinguishing features of PBL. More commonly, instructors introduce students to teacher determined content via lecture and texts. After a specific amount of content is presented, students are tested on their understanding in a variety of ways. PBL, in contrast, is more inductive: students learn the content as they try to address a problem. The "problems" in PBL are typically in the form of "cases", narratives of complex, real-world challenges common to the discipline being studied. There is no right or wrong answer; rather, there are reasonable solutions based on application of knowledge and skills deemed necessary to address the issue. The "solution" therefore is partly dependent on the acquisition and comprehension of facts, but also based on the ability to think critically. PBL, by having students demonstrate for themselves their capabilities, can increase students' motivation to tackle problems. Three major complaints from employers about college graduates are graduate's poor written and verbal skills, their inability to problem-solve, and their difficulties working collaboratively with other professionals. PBL can address all three areas.

However, the pedagogical technique used in this study is a combination of both PBL and traditional lectures. The students are given the basic theory in class; however the students understand the theory by solving real-world problems that are relevant to the theory.

\section{Introduction}

The transportation engineering is taught in the junior year as a required course for all civil engineering (CE) students. The course provides an introduction to various aspects of transportation engineering. The course, which is traditionally a lecture course, was redesigned to ensure that every student actively participates and understands the physical elements of transportation design. The students then have the option of taking an advanced transportation Design and Planning or pavement Design and Evaluation.

\section{Course Outline}

The course (Table 1) included six topics, 1) driver, pedestrian, vehicle and road characteristics,; 2) horizontal and vertical curves, and superelevation; 3) traffic stream flow; 4) Freeway- Levelof-service analysis; 5) Warrants; and 6) Simple signalized intersection. The class meets twice a week for 75 minutes each. 
Table 1. Course outline.

\begin{tabular}{c|c}
\hline Week & Topic \\
\cline { 1 - 1 } Week 1 & Introduction and Background \\
\cline { 1 - 1 } Week 2 & \multirow{2}{*}{ Driver, Pedestrian, Vehicle and Road Characteristics } \\
\cline { 1 - 1 } Week 3 & \multirow{2}{*}{ Horizontal and Vertical curves, and superelevation/Exam 1 } \\
\cline { 1 - 1 } Week 4 & Traffic Stream Flow/Exam 2 \\
\cline { 1 - 1 } Week 6 & Freeway \\
\cline { 1 - 1 } Week 7 & Week 8 \\
\cline { 1 - 1 } Week 9 & Simple Signalized Intersection \\
\hline Week 11 &
\end{tabular}

\section{Pedagogical Technique}

During the past four years the authors has tried innovative teaching techniques in a wide range of classes such as pavement materials ${ }^{1}$, surveying and engineering graphics ${ }^{2}$, and civil engineering materials ${ }^{3}$. Throughout this course, the author conducted a simulating and engaging exercise of requiring students to solve practical problems during class in teams of two immediately after covering the relevant theory. The practical problems were assigned before any example problems were solved in the class. Therefore, each class is divided into two parts, theory (30-35 $\%)$ and practical in-class problem solving $(60-65 \%)$.

For example immediately after a concept of vertical curve and its derivations from basic equations were covered, they solved a problem individually or in teams of two on determining the length of a curve necessary for providing enough clearance under a bridge (Figure 1). In this case they were asked to take the theory just covered and translate them to solving practical problems. During the class, the author answered any questions the groups may have while solving the problems. At the end, the problem was solved in class based on gathering information from the groups. At this time, the groups got a chance to compare their solution with the one solved in class. Eventually the correct solution was distributed (Figure 2). The class notes were supplemented with handouts from the AASHTO Policy of Geometric Design and Highway Capacity Manual.

A -4 \% grade and a $0 \%$ grade meet at station $24+00.00$ at elevation $2421.54 f t$. They are joined by an 800-ft vertical curve. The curve passes under an overpass at station $25+00.00$. If the lowest elevation of overpass is $2439.93 \mathrm{ft}$. Calculate available clearance.

Figure 1. A problem distributed to the class. 


\section{Impact of Technique}

The above mentioned pedagogical technique requires them to think through the problem. The students have to assimilate the information provided and translate it to the problem at-hand. This activity initially frustrated the students because they are traditionally used to following example problems. However, this exercise forced them to take the theoretical concepts and directly apply them to transportation engineering analysis and design problems.

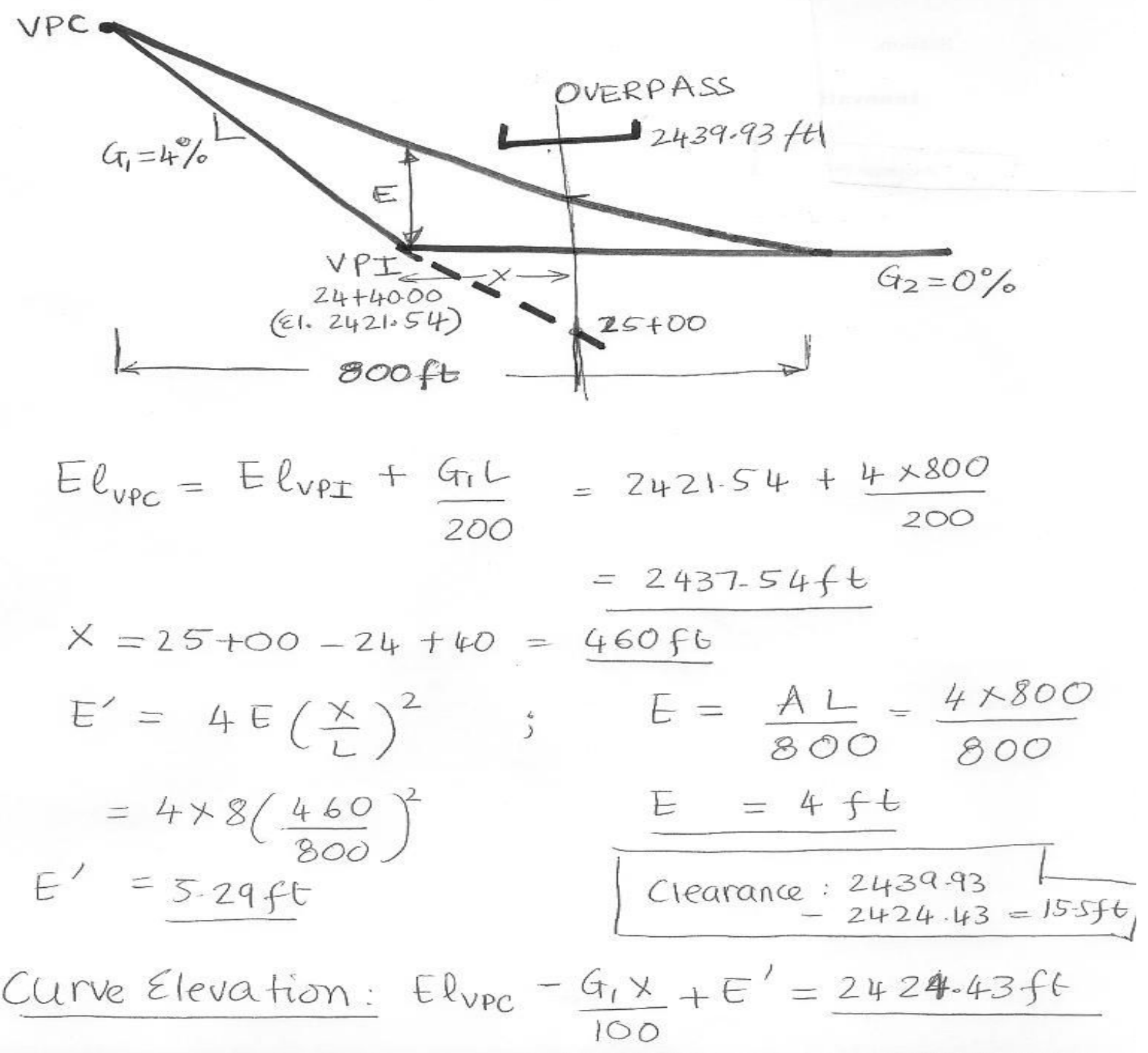

Figure 2. Handout with the solution.

Such an activity considerably increased the level of interest and provided a greater satisfaction of tackling the problem, rather than just following set example problems. On the other hand, the global learners remained engaged as they could visualize the relevance of the theory taught in 
class, and the more sequential learners after the initial struggle followed the problems through the explanation in class and the solution provided at the end of class. The author believes that the technique can be implemented in a 50- minute class, however, the number of in-class problems may have to be reduced.

\section{Homework, Exams and Quizzes}

All homework and exams were take-home and team-based. The homework were to be submitted within a week and the exams to be submitted within 48 to 72 hours, in which the team-members could discuss their effort as they presented their solutions to complex analysis and design problems. The take-home exams allowed the instructor to push the students to conduct complex analysis of existing transportation applications. The exam required them to refer to all available resources, beyond the textbook and the class notes to solve the problems. On the other hand, the quizzes were conceptual questions to be attempted by each student individually and it was closed book. The purpose of the quizzes was to evaluate if the students understand the concepts taught in the class. The quizzes were very short it took students an average of 10 minutes to answer the questions. The students who read the material have regularly performed well in the quizzes.

\section{Student Evaluation}

The instructor evaluation (Table 2) was very positive. The response to questions 2 and 5 (in bold) clearly showed that a significant percentage of students $(96 \%)$ were actively engaged in teaching and learning, and found the class stimulating. felt that the laboratory complimented well with the courses. The comments (Table 3 ) clearly showed that the students perceived the class positively. The students found the class to be challenging and liked the teaching style.

Table 2. Student Evaluations (68 students over four courses).

\begin{tabular}{c|l|c|c|c|c|c}
\hline & & \multicolumn{4}{|c}{ Student Scores (68 students) } \\
\hline & Question & $\begin{array}{c}\mathbf{1} \\
\text { (poor) }\end{array}$ & $\mathbf{2}$ & $\mathbf{3}$ & $\mathbf{4}$ & $\begin{array}{c}\mathbf{5} \\
\text { (excellent) }\end{array}$ \\
\hline 1 & $\begin{array}{l}\text { Was the professor enthusiastic about the } \\
\text { subject? }\end{array}$ & & & 1 & 6 & 61 \\
\hline $\mathbf{2}$ & Did the professor stimulate thinking? & & & $\mathbf{2}$ & $\mathbf{1 7}$ & $\mathbf{4 9}$ \\
\hline 3 & $\begin{array}{l}\text { Did the professor require a high level of } \\
\text { student performance? }\end{array}$ & & & 10 & 58 \\
\hline 4 & $\begin{array}{l}\text { Did the professor encourage questions and } \\
\text { comments during the class? }\end{array}$ & & & 1 & 13 & 54 \\
\hline $\mathbf{5}$ & $\begin{array}{l}\text { Did the professor actively involve } \\
\text { students in teaching and learning? }\end{array}$ & & $\mathbf{3}$ & $\mathbf{1 9}$ & $\mathbf{4 6}$ \\
\hline 6 & $\begin{array}{l}\text { Were handouts and assignments helpful for } \\
\text { understanding the subject? }\end{array}$ & & 2 & 22 & 44 \\
\hline
\end{tabular}

\section{Long Term Evaluation}

Several students have pursued transportation engineering after graduation and we have received favorable responses from the employers. This has been complemented by the employers seeking 
our students for employment in transportation engineering in subsequent years. The author also taught the same group of students in the advanced class of Transportation Design and Planning the following year. The author observed that they had a significant retention of the material and understood the concepts reasonably well. However, the instructor has not conducted a formal evaluation of student learning before and after the proposed technique study was implemented. Therefore a formal evaluation of the proposed technique is unavailable.

\section{Table 3. Student Comments}

\begin{tabular}{|c|c|}
\hline No & Comments \\
\hline 1. & Expected students to work hard, but in return we learned a great deal. \\
\hline 2. & $\begin{array}{l}\text { Methods of grade exams; should be more standardized. Questions should be more } \\
\text { clearly written. }\end{array}$ \\
\hline 3. & I enjoy the challenge he presents to the students. I like his teaching style. \\
\hline 4. & I enjoy the challenge. \\
\hline 5. & Great method of teaching. \\
\hline 6. & Good teacher. Expects a lot from students, but wants everyone to learn. \\
\hline 7. & $\begin{array}{l}\text { This class opened my eyes to a concentration of civil engineering that I really like. } \\
\text { Because of this class, I have interviewed with the DOT \& may end up in a transportation } \\
\text { career. }\end{array}$ \\
\hline 8. & $\begin{array}{l}\text { I really enjoy \& learn in this class. I think I will like to do an internship on transportation } \\
\text { maybe even go into transportation. Thank you for all your help. }\end{array}$ \\
\hline
\end{tabular}

\section{Applicability to other Engineering Courses}

The proposed technique is effective in courses, which require problems solving to enhance the understanding of the theory such as Fluid Mechanics, Geotechnical Engineering, Environmental Engineering, Pavement Design (Mehta et al. 2003a), Surveying and Engineering Graphics (Mehta et al. 2003b), and Structural Analysis. On the other hand, the material covered in Civil Engineering Materials course covers physical, mechanical behavior of aggregates, asphalt, cement concrete and aggregates (Mehta 2004). The information requires a more conceptual understanding of the materials and hence may not be appropriate to use this technique.

\section{Increase in Class Sizes}

The author found that this technique created a few unexpected problems, which were especially due to increase in class-size in the last couple of years. When the course was designed, there were 10-14 students; it was easier for the author to follow-up on the effort of students in class problems, where the most learning is happening. With the increase in class size to 28-30, it has become harder to pay close attention to all the students within the allotted time as they solve the in-class problems. However, the technique has still been effective. The author has supplemented the course with tutorial sessions beyond the class time to supplement the in-class problems. It has been very hard because at Rowan University no teaching assistants are assigned for the classes. It is unclear at this time at what critical class size this technique may become ineffective. 


\section{Conclusions}

Based on the four courses, the author strongly believes that the new technique is beneficial for both the instructor and the students. The methodology has been very effective; the students are very involved in the learning process and many have pursued career in transportation engineering. The author strongly believes that teaching is a learning process for the faculty. The author is continuously evolving and improvising the technique to ensure that the students stay current with the latest developments and have a fruitful learning environment.

\section{BIBLIOGRAPHICAL INFORMATION}

1. Gallow, De, "What is Problem Based Learning?" Instructional Resource Center, The William and Flora Hewlett Grant." http://www.pbl.uci.edu/whatispbl.html, 2006.

2. Scardamalia, M., and Bereiter C. "Student communities for the advancement of knowledge," Communications of the ACM Volume 39 No. 4 pp. 36 -37, 1996

3. Mehta, Y. and Najafi, F "Teaching Methodology of Flexible Pavement Materials and Pavement Systems," Journal of SMET Education, 2003a.

4. Mehta, Y. A, Orlins, J. and Lubelski, D. "Innovative Teaching Methods for Surveying and Engineering Graphics,” Proceedings of Mi-Atlantic Conference, Kean University, NJ 2003b.

5. Mehta, Y. A. "Innovative Techniques To Teach Civil Engineering Materials Laboratory," Proceedings of the ASEE Annual Conference, Salt Lake City, UT 2004. 